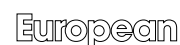

\title{
Editorial
}

\section{Addiction and Mental Health}

\author{
Michael Krausz
}

After many years of 'abstinence' and a delay of about 10 years as compared to the United States, comorbidity research has at last gained a foothold in Europe and has contributed a number of substantial studies. This was vastly due to clinical attentiveness and the practical problems that arise with these groups of patients. This was, in many European countries, also the main reason for activities in psychiatric and addiction research. The symptoms observed were more or less the same as those already described in the late 1970s and early 1980s by, e.g., Alterman [1] and his colleagues in Philadelphia and in other parts of the United States. Mentally ill addictive patients have greater problems with the existing help system, and they do not fit into the common treatment and rehabilitation programs. Comorbidity patients who are 'primarily addictive' and suffer from many affective disorders, suicidality or personality disorders are often insufficiently cared for both by maintenance and inpatient programs [2].

In the field of care and qualitative epidemiology, the big catchment area studies carried out in the United States, e.g. the ECA study [3] and the National Comorbidity Survey [4], also stimulated the development of similar systems, e.g., in German-speaking countries. The emergence of a research focus on qualitative epidemiology in the field of addiction is certainly one of the most important results of the promotion and development of research during the last 5 years. Based on this development, it might reasonably be expected that it will be possible also in the future to carry out field studies that will provide a realistic basis for the assessment of the problems of coand multimorbidity among addictive or psychiatric patients. Considering the high prevalence rate revealed for instance by the National Comorbidity Survey [4], the difference between addictive and psychiatric patients is perhaps not that great. However, the consequences for the treatment system are important because surveys carried out among the 'normal' population showed that the need for treatment is greatest among multimorbid patients.

This knowledge and its consequences for the treatment system have contributed clinically to the development of various treatment programs and their evaluation. Thus, the wealth of experience in dialectic behavioral therapy [5] is now also being exploited in the Netherlands and Germany by using it in the treatment of addictive patients with personality disorders. The tendencies to a greater clinical and scientific awareness in general psychiatry for the comorbidity problem and especially the coincidence of severe mental disorders and addiction, leading to special treatment offers with well-proven effectiveness, are of major importance. The most conspicuous example for new ways of treatment is the medical prescription of opiates for those heroin addicts that could not be reached by the help system. As reported in the Swiss study [6], among these patients there were many addicts with additional mental and physical problems who greatly benefited by the heroin maintenance treatment. Of course, the prescription of the original substance is not the only and perhaps not the most important ingredient of therapeutic success, but it prepares the ground for other, more differ-

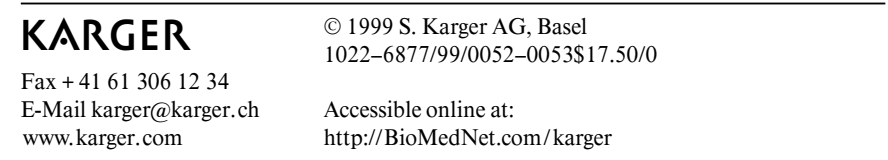


entiated therapies which might be psychopharmacological treatment or treatments of complex infectious diseases.

Last but not least, the development of the diagnostic methods and the adaptation of the Addiction Severity Index are important for a more differentiated view of, for instance, the consumption patterns of addictive patients or the extent of mental disorders and the resultant need for treatment.

The papers published in this issue take up quite a number of invariably relevant and controversial topics in the context of health and mental disorders. Thus, it is still unclear whether drug consumption plays an important part in the emergence of psychosis or whether it is just a kind of trigger in vulnerable individuals. It could not yet been proved that the prevalence rate of psychotic disorders is significantly higher in cannabis consumers than in the general population. It is also hardly possible (and as yet not done convincingly) to differentiate between symptoms due to intoxication and psychotic events independent of consumption. A similar discussion is starting for amphetamine consumption and the dangers of psychosis by, for instance, ecstasy.
The paper on alcohol consumption by addicts in maintenance treatment is an interesting addition to this topic, as well as the paper on the mental morbidity of heroin addicts in contact with the help system.

Some years ago in the much noticed debate on the positive effects of red wine on cardial health, it was shown that alcohol can also be discussed under the aspect of health promotion. But is it also possible that light drinking helps to stabilize mental health? This is an interesting question treated in the paper by Chick.

Another very personal paper, a supplement to the numerous scientific contributions, should find the interest of the colleagues. It focuses on one of the most important European addiction researchers and the co-founder of European Addiction Research, Ambros Uchtenhagen, who celebrated his 70th birthday last year. It would be difficult to find another retired person who actively creates new research traditions and contributes with enormous energy to the development of an infrastructure of European addiction research. It is a great privilege that another important European researcher and Swiss internationalist, Jules Angst, has written this personal laudatio to Ambros Uchtenhagen.

\section{References}

1 Alterman, AI: Substance abuse in psychiatric patients; in Alterman AI (ed): Substance Abuse and Psychopathology. New York, Plenum, 1985.

2 Krausz M, Verthein U, Degkwitz P, Haasen C, Raschke P: Maintenance treatment of opiate addicts in Germany with medications containing codeine - results of a follow-up study. Addiction 1998;93:1161-1167.

3 Regier DA, Farmer ME, Rae DS, Locke BZ, Keith SJ, Judd LL, Goodwin FK: Comorbidity of mental disorders with alcohol and other drug abuse. Results from the Epidemiologic Catchment Area (ECA) Study. JAMA 1990;264: 2511-2518.
4 Kessler RC, McGonagle KA, Zhao S, Nelson $\mathrm{CB}$, Hughes M, Eshleman S, Wittchen H-U, Kendler KS: Lifetime and 12-month prevalence of DSM-III-R psychiatric disorders in the United States: Results from the National Comorbidity Survey. Arch Gen Psychiat 1994;51: 8-19.

5 Frei A, Steffen T, Gasser M, Kummerle U, Stierli M, Dobler-Mikola A, Gutzwiller F, Uchtenhagen A: Economic evaluation in a trial of medically controlled prescription of narcotics to dependent users (PROVE). Soz.-Praventivmed 1998;43:185-194. 